\title{
Development of a Measure to Assess Patient Trust in Medical Researchers
}

\author{
Arch G. Mainous III, PbD ${ }^{1,3}$ \\ Daniel W. Smith, $P b D^{2}$ \\ Mark E. Geesey, $M S^{1}$ \\ Barbara C. Tilley, $P b D^{3}$ \\ 'Department of Family Medicine, \\ Medical University of South Carolina, \\ Charleston, SC \\ ${ }^{2}$ Department of Psychiatry, Medical Uni- \\ versity of South Carolina, Charleston, SC \\ ${ }^{3}$ Department of Biostatistics, Bioinformatics \\ and Epidemiology, Medical University of \\ South Carolina, Charleston, SC
}

\begin{abstract}
PURPOSE Many researchers find it difficult to recruit individuals, particularly minorities, for participation in studies. Mistrust of research and researchers may act as a barrier to participation. The purpose of this study was to develop a scale for assessing trust in medical researchers.
\end{abstract}

METHODS We developed a multi-item scale by means of multiple cognitive pretests with 25 African American adults and a random-digit-dialing telephone survey of 512 adults in South Carolina. Psychometric characteristics of the Trust in Medical Researchers Scale was assessed by factor analysis using both orthogonal and oblique rotations and Cronbach's $\alpha$. We assessed construct validity as well as a behavioral intention for future participation in a medical research project.

RESULTS The results of the orthogonal and oblique rotations in the exploratory factor analysis were similar and suggested 2 distinct factors in the final 12 items included in the scale. Cronbach's $\alpha$ for the entire scale was 0.84 , whereas it was 0.78 for the first factor of Participant Deception and 0.75 for the second factor of Researcher Honesty. White respondents $(28.7 \pm 5.6)$ had greater trust than African American respondents $(24.1 \pm 6.9)(P<.001)$. Individuals with high trust in medical researchers were more likely to express interest in future participation in medical research.

CONCLUSIONS The Trust in Medical Researchers Scale has good psychometric qualities and differentiates African American from white respondents, as well as individuals who indicate that they are likely to participate in medical research from those who are not. More focused investigations in hard-to-recruit populations will help to establish the utility of the Trust in Medical Researchers Scale.

Ann Fam Med 2006;4:247-252. DOI: 10.1370/afm.541.

\section{INTRODUCTION}

$\mathrm{A}$ common barrier to the development of new knowledge, particularly for medical problems affecting minority populations, is the ability to enroll patients. Although the National Institutes of Health requires inclusion of women, minorities, and children into new protocols, recruitment of minorities into medical research is an ongoing challenge. The concept of trust is important, not only for the delivery of care but also for the participation of patients in medical research. In several studies of patients participating or declining to participate in clinical trials of cancer therapy, one of the most common reasons for participating is the advice of or trust in the doctor. ${ }^{1,2}$ Focus group data exemplify the critical role of trust in their doctor, as well as other entities in the health care system, when examining participation of African American adults in medical research. African American patients describe distrust in the medical community as a prominent barrier to participation in clinical research. ${ }^{3}$

Most scales focusing on trust issues in health care have been focused on patient-physician trust. ${ }^{4-9}$ Other measures have focused on patient trust in health insurers and physicians in general rather than the individual physician. ${ }^{10-13}$ One measure in particular focused on patient mistrust of 
hospitals. ${ }^{14}$ Consequently, although data suggest that some individuals and minority elders, in particular, have trust issues with multiple agents within the health care system, and that these issues may affect participation in medical research, there is currently no measure that allows for an assessment of trust in medical researchers.

By focusing on an individual's level of trust in medical researchers, it may be possible to identify communityspecific concerns about medical researchers and address those community-specific concerns in recruitment efforts. The purpose of this study was to develop a measure that will assess adults' trust in medical researchers.

\section{METHODS}

The process involved in developing the measure included developing a conceptual model, creating potential items, evaluating those items in a cognitive pretest, and examining the psychometric characteristics of the items and the measure in the general population. We developed a conceptual model of trust based on a review of the limited theoretical literature in medical settings and the literature on trust in nonmedical settings. Several themes we investigated were a general fear of participation in medical research, mistrust of research personnel, and feelings that researchers act differently toward disadvantaged groups. Based on the psychometric data described below, this general grouping of constructs later focused on trust in medical researchers rather than the more general construct of trust in the medical research process.

\section{Item Generation and Selection}

We used our conceptual model and data from a variety of studies appearing in the literature that have already been conducted on trust in medical research, particularly with African American respondents, to create initial categories of items. We examined items from existing scales to create an initial pool of 29 items for indepth pretesting. These items fell into 3 general theoretical dimensions: (1) fear of medical research, (2) mistrust of research personnel, and (3) perceived mistreatment of minority and disadvantaged respondents.

The items underwent a cognitive pretest of thinkaloud interviews with 25 African American volunteers (young adults and older adults) in South Carolina. Because the entire research team was white and other informal pretests of the items were conducted on white volunteers, we believed it was important to conduct think-aloud interviews with African Americans, particularly because African Americans have lower participation rates in medical research, it was not our intention to create scales for separate racial/ethnic groups. These interviews were conducted in 2 rounds with modi- fications made to the items after each round. After these interviews and the subsequent modifications and deletion of some of the poorly understood items, a questionnaire of 27 candidate items was developed for evaluation in the general population test designed to provide psychometric information. Each item was answered on a 5-point Likert scale and scored accordingly $(1=$ strongly disagree, $2=$ disagree, $3=$ neutral, $4=$ agree, $5=$ strongly agree). So that higher scores would always represent more trust in medical researchers, certain items were scored in reverse order.

\section{Psychometric Evaluation}

In an effort to develop the measure and evaluate it psychometrically in a more generalized context, the Survey Research Unit of the Medical University of South Carolina was contracted to conduct a survey of adults (older than 18 years) living in South Carolina between March 2005 and June 2005. The survey design included a random-digit dialing technique to generate telephone numbers using the Genesys Sampling System. A sample of 6,300 randomly-generated numbers was restricted to area codes and prefixes associated with the state of South Carolina. Each number was called 5 times or until a terminal disposition code (eg, nonworking number, not a private residence, language barrier) was assigned. The interviewers identified themselves as calling from the Medical University of South Carolina and conducting a survey on trust in medical research. They asked to speak to an adult older than 18 years. Only 1 person was interviewed per household. The interview lasted approximately 20 minutes. More information regarding specific technical aspects of the survey administration can be obtained from the authors.

There were 512 respondents who completely or partially answered all the interview questions and 558 eligible respondents who refused, for a response rate of $47.8 \%$. Because of the nature of the random-digit dialing design with computer selection of the numbers, no information was available on the nonresponders. Interview responses were entered into an electronic database directly by the interviewer as the respondent replied to questions. Appropriate range and logic checks were incorporated into the data entry process.

We conducted an initial examination of the descriptive characteristics of each of the potential items, including their distributions and variance. All the potential items showed sufficient distribution across the response categories to warrant inclusion in further analyses, although several exhibited bimodal distributions.

We conducted a series of analyses focusing on data-reduction techniques and psychometric properties of the scale using SAS 9.1 (SAS Institute, Cary, NC). We initially used a principal components analysis 
of the 27 items to examine the latent dimensions of the scale and to reduce the number of items to only those that loaded with high loadings on a single factor. After we examined the unrotated factor matrix to determine loadings on 1 general latent dimension, we then rotated the factor structure by means of both an orthogonal rotation using a VARIMAX rotation and an oblique rotation using PROMAX, because of considerable conceptual overlap in the hypothesized dimensions. After reviewing the factor loadings, we again examined the items both mathematically and conceptually.

In this stage of the analysis, internal consistency of the scale was assessed through the use of Cronbach's coefficient $\alpha$. We examined the factors and the total group of items to determine whether the new measure of trust in medical researchers could be used to give a global score or subscale scores.

Concurrent validation suggesting initial evidence of construct validity was assessed by correlating the new measure with other measures of trust in health care system entities, as well as a global assessment of trust. The Trust in Health Insurer scale was asked of respondents who had medical health insurance. ${ }^{11}$ The Trust in Physicians scale was asked of respondents who had a regular doctor. ${ }^{4}$ Finally, to determine the degree to which items on the new scale assessed a respondent's global sense of mistrust, we also administered 3 items from the Cynicism scale of the Minnesota Multiphasic Personality Inventory-2 (MMPI-2). ${ }^{15}$ These 3 items were, "I think most people would lie to get ahead," "It is safer to trust nobody," and "Most people will use somewhat unfair means to get ahead in life." These true-false items were summed (range 0 to 3 ) to create an index of general suspiciousness, with higher scores reflecting greater mistrust and cynicism.

In an effort to gain an understanding of how the constructs of trust in medical researchers may affect participation in medical research, the following item regarding behavioral intention was assessed: "If you were approached by someone at the Medical University of South Carolina to participate in a study, how likely would you be to volunteer to participate in a study in the next 3 months?" This item was measured in terms of likely, somewhat likely, not likely, or not likely at all to participate.

We used $t$ tests to examine scale scores by demographic characteristics and Pearson correlation analyses to compare the scores from the Trust in Medical Researchers Scale with these other scales and the single item about likelihood of volunteering for a medical research program. Because some of the additional scales used to establish construct validity were conditional on the respondent having a regular physician or health insurance, analyses were conducted only for those respondents for whom we had a full set of data for those comparisons. Finally, we analyzed the Trust in Medical Researchers Scale with the likelihood of future participation in medical research. We investigated this relationship in 2 ways. First, we split the Trust in Medical Researchers Scale into low and high and the 4-category likelihood variable into likely or not likely and computed $\chi^{2}$ analysis to examine its relationship. We also computed analyses of variance by using all 4 categories of the likelihood variable and leaving the Trust in Medical Researchers Scale as a continuous variable.

This study was approved by the Institutional Review Board of the Medical University of South Carolina.

\section{RESULTS}

Of the 512 persons who responded to the telephone survey, 496 answered enough questions to be used for analyses. The racial distribution of the sample consisted of 354 white (71.4\%), 116 African American $(23.4 \%), 19$ other $(3.8 \%)$, and 7 unknown $(1.4 \%)$. There were 165 men $(33.3 \%), 328$ women $(66.1 \%)$, and 3 unknown $(0.6 \%) ; 72(14.5 \%)$ respondents had less than a high school education, and 279 (56.3\%) had at least some college education.

Using data from the 400 respondents who answered all 27 of the initial questions to be evaluated for inclusion in the scale, the initial unrotated factor analysis based on principal components identified 12 items that loaded high on a single factor were retained $(\geq 0.50)$ (Table 1). This single factor, with an eigenvalue greater than 1.0, was also identified through a scree test. Using data from the 448 respondents who answered all 12 of these questions, these 12 items were then subjected to orthogonal rotations using VARIMAX and oblique rotations of the factor matrix using PROMAX. The rotated factor matrix identified 2 primary factors. Table 1 presents the factor loadings for both the orthogonal and oblique rotations that show a high degree of similarity. Internal consistency, as measured by Cronbach's $\alpha$, was high for the entire 12 -item questionnaire $(\alpha=0.842)$. For each of the 12 items on the scale, the item-to-total correlation ranged from 0.822 to 0.837 (Table 1 ).

The scores from the 12 items are summed unweighted, and 12 is subtracted from the total, yielding a Trust in Medical Researchers Scale score ranging from 0 to 48 . The higher the score, the greater the trust in medical researchers. Two subscales were developed corresponding to the 2 identified factors. Item numbers 1 to 6 (Table 1) load onto factor 1 (participant deception) and items 7 to 12 load onto factor 2 (researcher honesty). The Cronbach's $\alpha$ for factor 1 


\begin{tabular}{|c|c|c|c|c|c|c|}
\hline \multirow[b]{2}{*}{ No. } & \multirow[b]{2}{*}{ Item } & \multicolumn{2}{|c|}{$\begin{array}{l}\text { Orthogonal } \\
\text { Rotation }\end{array}$} & \multicolumn{2}{|c|}{$\begin{array}{l}\text { Oblique } \\
\text { Rotation }\end{array}$} & \multirow{2}{*}{$\begin{array}{c}\alpha \text { If } \\
\text { Item Is } \\
\text { Deleted }\end{array}$} \\
\hline & & PD & RH & PD & RH & \\
\hline 1 & $\begin{array}{l}\text { To get people to take part in a study, medical researchers usually do not explain } \\
\text { all of the dangers about participation.* }\end{array}$ & 0.445 & 0.415 & 0.536 & 0.514 & 0.829 \\
\hline 2 & $\begin{array}{l}\text { Participants should be concerned about being deceived or misled by medical } \\
\text { researchers.* }\end{array}$ & 0.614 & 0.176 & 0.639 & 0.326 & 0.833 \\
\hline 3 & Usually, researchers who make mistakes try to cover them up.* & 0.611 & 0.346 & 0.679 & 0.490 & 0.824 \\
\hline 4 & $\begin{array}{l}\text { Medical researchers act differently toward minority subjects than toward white } \\
\text { subjects.* }\end{array}$ & 0.671 & 0.184 & 0.695 & 0.348 & 0.829 \\
\hline 5 & $\begin{array}{l}\text { Medical researchers unfairly select minorities for their most dangerous research } \\
\text { studies.* }\end{array}$ & 0.780 & 0.169 & 0.798 & 0.361 & 0.823 \\
\hline 6 & $\begin{array}{l}\text { Some medical research projects are secretly designed to expose minority groups } \\
\text { to diseases such as AIDS." }\end{array}$ & 0.700 & 0.062 & 0.693 & 0.237 & 0.833 \\
\hline 7 & $\begin{array}{l}\text { Medical researchers are generally honest in telling participants about different } \\
\text { treatment options available for their conditions. }\end{array}$ & 0.129 & 0.655 & 0.292 & 0.666 & 0.834 \\
\hline 8 & Usually, medical researchers tell participants everything about possible dangers. & 0.255 & 0.667 & 0.417 & 0.710 & 0.827 \\
\hline 9 & $\begin{array}{l}\text { All in all, medical researchers would not conduct experiments on people without } \\
\text { their knowledge. }\end{array}$ & 0.046 & 0.681 & 0.219 & 0.671 & 0.837 \\
\hline 10 & $\begin{array}{l}\text { Most medical researchers would not lie to people to try to convince them to } \\
\text { participate in a research study. }\end{array}$ & 0.143 & 0.614 & 0.295 & 0.630 & 0.835 \\
\hline 11 & $\begin{array}{l}\text { In general, medical researchers care more about doing their research than about } \\
\text { the participants' medical needs.* }\end{array}$ & 0.355 & 0.522 & 0.476 & 0.595 & 0.829 \\
\hline 12 & $\begin{array}{l}\text { Researchers are more interested in helping their careers than in learning about } \\
\text { health and disease.* }\end{array}$ & 0.453 & 0.545 & 0.578 & 0.642 & 0.822 \\
\hline
\end{tabular}

is 0.776 and for factor 2 is 0.749 . The subscale scores are calculated as follows:

Participant deception $=[($ sum of items 1 to 6) -6] $* 2$.

Researcher honesty $=[$ (sum of items 7 to 12$)-6]^{*} 2$.

The range of each subscore is the same as for the overall Trust in Medical Researchers Scale (0 to 48). As with the overall score, higher scores indicate greater trust in medical researchers. The participant deception subscale was correlated with the researcher honesty subscale at $r=.60(P=.001)$.

Means and standard deviations were calculated for each score and for various race, sex, age, and education groups (Table 2). White respondents $(28.7 \pm 5.6)$ had higher scores on the full scale than African American respondents $(24.1 \pm 6.9)$ $(P<.001)$. Similarly, white respondents were significantly higher on the participant deception subscale $(27.8 \pm 6.3)$ than African American respondents $(22.0 \pm 7.6)(P<.001)$.
Table 2. Means and Standard Deviation for the Overall Trust in Medical Researchers Scale Score and Each of the Subscores by Race

\begin{tabular}{|c|c|c|c|c|}
\hline Subgroups & Number & $\begin{array}{l}\text { Overall } \\
\text { TIMRS }\end{array}$ & $\begin{array}{l}\text { Participant } \\
\text { Deception }\end{array}$ & $\begin{array}{c}\text { Researcher } \\
\text { Honesty }\end{array}$ \\
\hline \multicolumn{5}{|l|}{$\overline{\text { Sex }}$} \\
\hline White, male & 111 & $29.1(5.5)$ & $28.1(6.3)$ & $30.1(5.9)$ \\
\hline White, female & 208 & $28.6(5.6)$ & $27.7(6.3)$ & $29.5(6.3)$ \\
\hline African American, male & 32 & $24.7(7.1)^{*}$ & $22.1(8.2)^{*}$ & $27.3(7.6)^{*}$ \\
\hline African American, female & 73 & $23.9(6.8)^{\dagger}$ & $22.0(7.4)^{\dagger}$ & $25.8(7.8)^{\dagger}$ \\
\hline Other, male & 10 & $24.8(4.5)$ & $26.0(7.2)$ & $23.6(5.9)$ \\
\hline Other, female & 6 & $24.7(4.1)$ & $23.7(4.5)$ & $25.7(5.1)$ \\
\hline \multicolumn{5}{|l|}{ Age } \\
\hline White, $<55$ y & 159 & $29.6(5.4)$ & $28.7(6.1)$ & $30.5(6.0)$ \\
\hline White, $\geq 55 \mathrm{y}$ & 161 & $28.0(5.6)^{\ddagger}$ & $26.9(6.4)^{\ddagger}$ & $29.0(7.0)^{\ddagger}$ \\
\hline African American, $<55$ y & 69 & $24.8(6.7)^{\ddagger}$ & $22.7(7.9)^{\ddagger}$ & $26.9(7.4)^{\ddagger}$ \\
\hline African American, $\geq 55 \mathrm{y}$ & 33 & $22.7(7.0)^{\S}$ & $20.6(6.9)^{\S}$ & $24.8(8.1)^{\S}$ \\
\hline \multicolumn{5}{|l|}{ Education } \\
\hline White, $\leq$ high school & 130 & $27.5(5.3)$ & $26.2(6.2)$ & $28.9(5.9)$ \\
\hline White, $\geq$ some college & 190 & $29.6(5.6)^{\|}$ & $28.9(6.1)^{\|}$ & $30.3(6.1)^{\|}$ \\
\hline African American, $\leq$ high school & 64 & $24.3(6.2)^{\|}$ & $22.0(5.6)^{\|}$ & $26.6(7.3)^{\|}$ \\
\hline African American, $\geq$ some college & 41 & $23.9(7.9)^{4}$ & $22.1(9.1)^{9}$ & $25.7(8.4)^{\natural}$ \\
\hline \multicolumn{5}{|l|}{ TIMRS $=$ Trust in Medical Researches Scale. } \\
\hline $\begin{array}{l}\text { * Significantly different from white mal } \\
\text { † Significantly different from white fem } \\
\text { † Significantly different from white part } \\
\text { \& Significantly different from white part } \\
\text { ॥ Significantly different from white part } \\
\text { I Significantly different from white part }\end{array}$ & $\begin{array}{l}\text { participants ( } \\
\text { e participants } \\
\text { ipants }<55 \text { ye } \\
\text { ipants } \geq 55 \text { yea } \\
\text { ipants with hig } \\
\text { ipants with at I }\end{array}$ & $\begin{array}{l}<.05) \\
<.05) \\
\text { is }(P<.05) \\
(P<.05) \\
\text { school educ } \\
\text { ast some col }\end{array}$ & less $(P<.0$ & \\
\hline
\end{tabular}


White respondents also scored significantly higher on the researcher honesty subscale $(29.7 \pm 6.1)$ than African American respondents $(26.3 \pm 7.7)(P<.001)$.

Within racial groups (white, African American, other) there were no differences by sex in mean scores for the overall scale or for the subscales (Table 2). There were too few respondents in the "other" racial group $(\mathrm{n}=16)$ to make statistically significant comparisons. African American respondents of both sexes scored significantly lower than white respondents of the same sex on the overall scale, as well as on both of the subscales $(P<.05)$.

White respondents aged less than of 55 years scored significantly higher on the overall scale and on the 2 subscales than white respondents aged 55 years and older. The same trend was observed for African American respondents, but the differences were not significant $(P>.05)$ because of the smaller sample numbers. In comparison by race within each age-group, African American respondents scored significantly lower than white respondents $(P<.05)$.

White respondents with at least some college education scored significantly higher on the overall Trust in Medical Researchers Scale than white respondents with a high school education or less. They also scored significantly higher on the 2 subscales $(P<.05)$. For African American respondents, there were no significant differences in mean scores between the education groups. African American respondents of both education groups scored significantly lower than their white counterparts on the overall scale and on the 2 subscales.

Some evidence toward construct validity is found from the correlation analyses between the Trust in Medical Researchers Scale overall score and the 2 subscales with other trust scales (Table 3).

Any respondent who gave a neutral response to every item would score 24 . Respondents who scored at least 24 on the overall Trust in Medical Researchers Scale or either of the 2 subscales were much more likely to say that they would be likely or somewhat likely to volunteer to participate in a research program than respondents who scored less than 24 (Table 4). When ANOVAs were

\section{Table 3. Pearson Correlation Coefficients Between the Trust in Medical Researchers Scale and Subscale Scores With Other Established Trust Measures: Health Insurance Trust Scale, Trust in Physicians Scale, Cynicism}

\begin{tabular}{lccc}
\hline $\begin{array}{l}\text { Trust in Medical } \\
\text { Researchers Scale }\end{array}$ & $\begin{array}{c}\text { Health Insurance } \\
\text { Trust Scales }\end{array}$ & $\begin{array}{c}\text { Trust in } \\
\text { Physicians Scale }\end{array}$ & Cynicism \\
\hline Total scale & $0.290^{*}$ & $0.263^{*}$ & $-0.380^{*}$ \\
Participant deception subscale & $0.281^{*}$ & $0.183^{\dagger}$ & $-0.377^{*}$ \\
Researcher honesty subscale & $0.248^{*}$ & $0.300^{*}$ & $-0.305^{*}$ \\
\hline$* P<.001$. & & & \\
$\dagger P<.005$. & & & \\
\hline
\end{tabular}

Table 4. Relation of Trust in Medical Researchers Scale Scores by Likelihood of Volunteering to Participate in Future Research

\begin{tabular}{lcc}
\hline Scores & $\begin{array}{c}\text { Percent Likely } \\
\text { to Volunteer }\end{array}$ & $\chi^{2} P$ Value \\
\hline Overall TIMRS & 49.1 & \\
$<24$ & 71.4 & $<.001$ \\
$\geq 24$ & & \\
Patient deception & 57.5 & $<.01$ \\
$<24$ & 69.9 & \\
$\geq 24$ & & \\
Researcher honesty & 45.5 & $<.001$ \\
$<24$ & 71.0 & \\
$\geq 24$ & & \\
\hline TIMRS = Trust in Medical Researchers Scale. & \\
\hline
\end{tabular}

computed with the 4-category likelihood variable and the Trust in Medical Researchers Scale as a continuous variable, the full scale $(\mathrm{F}=9.64, d f=3, P=.001)$, the participant deception subscale $(\mathrm{F}=4.67, \mathrm{df}=3, P=$ $.003)$, and the researcher honesty subscale $(\mathrm{F}=12.33$, df $=3, P=.001$ ), all yielded significant relationships with likelihood of future participation in medical research.

\section{DISCUSSION}

A person's trust in medical researchers is a barrier to participation in medical research. We have created the Trust in Medical Researchers Scale, a short self-administered scale with good psychometric properties that can assess an person's trust in medical researchers. The Trust in Medical Researchers Scale differentiates African American respondents from white respondents, as well as by the stated likelihood of participation in future research. Thus, there appears to be substantial potential utility of the Trust in Medical Researchers Scale for investigators trying to recruit ethnic populations that historically have been hard to reach.

If future investigations into the utility of this scale appear promising, we envision researchers using it to screen populations of interest regarding mistrust in medical researchers. For example, if an investigator is interested in recruiting a racially diverse sample for participation in an Alzheimer's study, then this scale could be administered to a representative sample of the community to identify issues that might affect recruitment. Investigators could then subsequently tailor their recruitment efforts or community education of the project based on the information 
gained from the scale. In addition to examining community belief systems, the scale might also be used to examine the trust in medical researchers of health care practitioners. Because health care practitioners are many times the point of recruitment, at least discussions with patients about participation in studies assessing their trust might suggest points of education or interventions. Further, practice-based research networks are a key strategy in developing primary care research infrastructure and are based on participation by health care practitioners, many of whom are not directly affiliated with academic settings. Assessing the trust in medical researchers among community physicians may help in identifying barriers to recruitment of physicians to practice-based research networks.

There are several limitations to this study. First, the cognitive pretests were conducted with African Americans, and although these tests would be beneficial in the development of a scale to assess trust in medical researchers because of this group's documented mistrust of the medical care system, the resulting items may not generalize to other populations. ${ }^{16} \mathrm{We}$ attempted to gain a better understanding of the scale items for the general population by means of the random-digit dialing telephone survey. It may be useful to validate this tool in other populations.

Second, the Trust in Medical Researchers Scale was designed to be self-administered. The cognitive pretests allowed a person to read the items and then discuss them, which approximates the ultimate use of the scale. We used a telephone survey to collect data from the general population by reading the items to the respondents, which may be similar to what large-scale community assessments do. Thus, additional work may need to be done to evaluate the scale in the context of self-administration.

Third, the response rate to the random-digit dialing telephone sample was less than optimal, although not unusual in contemporary times for a survey with no incentive payment to respond. Furthermore, the educational level of the respondents was higher than would be expected and thereby may indicate a sample that was less than representative, which would bias the results toward the null. The results, however, indicate that the Trust in Medical Researchers Scale does distinguish individuals by race/ethnicity, education, and reported likelihood of future participation in medical research.

Fourth, the Trust in Medical Researchers Scale was developed primarily on samples of white and African American respondents. Future research could focus on validating this scale in other minority or hard-to-reach populations.

In conclusion, the Trust in Medical Researchers Scale shows promise as a tool for identifying individuals or groups of individuals who are unlikely to participate in medical research. It is currently unclear as to whether the scale will best be used as a 12 -item scale or as separate subscales. As the primary care research community becomes more aware of the need for inclusion of diverse populations in studies that truly represent the primary care patient population, the issue of barriers to recruitment and participation take on greater importance. This scale appears to be a useful tool in the armamentarium of researchers.

To read or post commentaries in response to this article, see it online at http://www.annfammed.org/cgi/content/full/4/3/247.

Key words: Trust; data collection; scale development

Submitted September 29, 2005; submitted, revised, November 30, 2005; accepted December 26, 2005.

Funding support: This study was supported in part by grant 1 P30AG021677 from the National Institute on the Aging.

\section{References}

1. Jenkins V, Fallowfield L. Reasons for accepting or declining to participate in randomized clinical trials for cancer therapy. Br J Cancer. 2000;82:1783-1788.

2. Daugherty C, Ratain MJ, Grochowski E, et al. Perceptions of cancer patients and their physicians involved in phase I trials. J Clin Oncol. 1995;13:1062-1072.

3. Corbie-Smith G, Thomas SB, Williams MV, Moody-Ayers S. Attitudes and beliefs of African Americans toward participation in medical research. J Gen Intern Med. 1999;14:537-546.

4. Anderson LA, Dedrick RF. Development of the Trust in Physician scale: a measure to assess interpersonal trust in patient-physician relationships. Psychol Rep. 1990;67:1091-1100.

5. Thom DH, Ribisl KM, Stewart AL, Luke DA. Further validation and reliability testing of the Trust in Physician Scale. The Stanford Trust Study Physicians. Med Care. 1999;37:510-517.

6. Kao AC, Green DC, Davis NA, Koplan JP, Cleary PD. Patients' trust in their physicians: effects of choice, continuity, and payment method. J Gen Intern Med. 1998;13:681-686.

7. Safran DG, Kosinski M, Tarlov AR, et al. The Primary Care Assessment Survey: tests of data quality and measurement performance. Med Care. 1998;36:728-739.

8. Leisen B, Hyman MR. An improved scale for assessing patients' trust in their physician. Health Mark Q. 2001;19:23-42.

9. Hall MA, Zheng B, Dugan $E$, et al. Measuring patients' trust in their primary care providers. Med Care Res Rev. 2002;59:293-318.

10. Kao AC, Green DC, Zaslavsky AM, Koplan JP, Cleary PD. The relationship between method of physician payment and patient trust. JAMA. 1998;280:1708-1714.

11. Zheng B, Hall MA, Dugan E, Kidd KE, Levine D. Development of a scale to measure patients' trust in health insurers. Health Serv Res. 2002;37:187-202.

12. Hall MA, Camacho F, Dugan E, Balkrishnan R. Trust in the medical profession: conceptual and measurement issues. Health Serv Res. 2002;37:1419-1439.

13. Thompson HS, Valdimarsdottir HB, Winkel G, Jandorf L, Redd W. The Group-Based Medical Mistrust Scale: psychometric properties and association with breast cancer screening. Prev Med. 2004;38:209-218

14. LaVeist TA, Nickerson KJ, Bowie JV. Attitudes about racism, medical mistrust, and satisfaction with care among African American and white cardiac patients. Med Care Res Rev. 2000;57 Suppl 1:146-161.

15. Butcher JN, Graham JR, Williams CL, Ben-Porath Y. Development and Use of the MMPI-2 Content Scales. ed. Minneapolis, MN: University of Minnesota Press; 1989.

16. Brandon DT, Isaac LA, LaVeist TA. The legacy of Tuskegee and trust in medical care: is Tuskegee responsible for race differences in mistrust of medical care? J Natl Med Assoc. 2005;97:951-956. 